\title{
EFFECT OF HABITAT FACTORS AND PREDATOR DENSITY ON THE SPATIAL ABUNDANCE OF CAPE HARE (LEPUS CAPENSIS) IN THE KARAKORUM RANGE
}

\author{
ZAMAN, M. ${ }^{1,2 \#}-$ RAKHA, B. A. ${ }^{2 \#}-$ BAO, H. ${ }^{1 \#}-$ VITEKERE, K. ${ }^{1 \#}-$ JIANG, G..$^{1 *}$ \\ ${ }^{I}$ Feline Research Center of National Forestry and Grassland Administration, College of \\ Wildlife and Protected Areas, Northeast Forestry University,26 Hexing Road,Harbin 150040, \\ China \\ ${ }^{2}$ Department of Wildlife Management, Pir Mehr Ali Shah Arid Agriculture University, \\ Rawalpindi 46300, Pakistan \\ ${ }^{\#}$ These authors contributed equally to this work. \\ *Corresponding author \\ e-mail: jgshun@126.com; phone: +85-0451-82190-279 \\ (Received $7^{\text {th }}$ Nov 2019; accepted $12^{\text {th }}$ Feb 2020)
}

\begin{abstract}
In fragmented landscapes, the accessibility of resources not only influences the spatial distribution of the predators themselves, but may similarly affect the abundance of their prey. We studied the influence of habitat dynamics and predator density on the spatial abundance of Cape hare (Lepus capensis) in the Karakorum Range in a $5700 \mathrm{~km}^{2}$ area in Shigar valley during 2015-16 and 2017. We found that, seasonally the population density of Cape hare at deciduous forest plantation (site 3), was the highest and the lowest density of Cape hare was found in the closed to open herbaceous vegetation (site 1). Seasonally the detection probability and encounter rate were found the highest in the closed to open herbaceous vegetation (site 1), and detection probability was the lowest in the grassland and bare lands (site 2). In summer, we found a positive correlation between Cape hare and Red fox density in the deciduous forest plantation (site 3). In winter, a positive relationship between Cape hare and Red fox density were observed in the grassland and bare lands (site 2). Seasonally, the density of Cape hare were the highest recorded in the deciduous forest plantation (site 3) where the relative density of Red fox and encounter rate of active burrows were the lowest. In this economically poor study area, humans often retaliate against damages caused by local wildlife using guns. The conclusions are discussed in the perspective of predator - prey interaction and the implications for management and mitigation of human - wildlife conflicts are also considered.
\end{abstract}

Keywords: distance samplings, habitat factors, human - wildlife conflict, predator-prey, seasonal estimation

\section{Introduction}

Prey population density can fluctuate in responses to both lethal and non-lethal effects caused by predators (Preisser et al., 2005). In such habitats with the presence of predators, the prey is likely to be more alert, to lower the risk of being killed (Brown et al., 1999). For prey species, the decision of when and how to escape from a potential threat is a complex process that is subject to relations between numerous biotic and abiotic factors (Stankowich and Blumstein, 2005). Typically, herbivore behavior is divided into three main activity types: grazing, resting and moving (Arnold and Dudzinski, 1978). These activities have significant impacts within the landscape (both spatial and temporal distribution, and habitat and vegetation preference) (Lima, 1998). It has been shown that both natural predation and anthropogenic threats cause similar behaviors such as increased alertness in herbivores (Lima and Dill, 1990). These risk effects are negatively influence foraging efficiency (Møller, 2008). 
Predation risk effects are dependent on the body-size of prey like small (e.g. rodent) and medium-sized prey (e.g. lagomorph). Medium-sized prey in open habitat is able to run fast, and in dense habitats, prey are expected to persist due to the availability of refuge (Waggett and Buskey, 2007). Cape hare is a medium-sized herbivore and active at night time or day time as well as hares have adopted a very strong active anti-predator tactic; such as they can leap and immobile (Weterings et al., 2016). The predation risk on hare is increased as they cannot depend on a burrow system (Creel, 2011). The obtainability and quality of resources influences the size of animal home range (Macdonald, 1983), such that, in canids for example, a home range in a resource-rich area may be smaller than in a resource-poor area (e.g., $0.4 \mathrm{~km}^{2}$ and $>40 \mathrm{~km}^{2}$, respectively, Macdonald, 2004). Furthermore, den selection is influenced by prey availability in the corsac red fox (Vulpes corsac) (Murdoch et al., 2009), the Eurasian badger (Meles meles) and the red fox (Márton et al., 2016).

However, Red foxes prey on hares (Goszczyński and Wasilewski, 1992a), and utilize dens for birthing and rearing offspring ('breeding dens') and as resting sites outside the breeding periods ('non-breeding dens) (Meia and Weber, 1992). Predator and preys interaction in a landscape were demonstrated by Hearn et al. (1987), that decreasing in the survival rate of juvenile arctic hares (Lepus arcticus) in Newfoundland was predation by the red fox (Vulpes vulpes). Santilli et al. (2007) defined that high Red fox predation was related to the mortality of European hares (Lepus europaeus) in Italy. Furthermore, in Sweden, Artic hare (Lepus timidus) densities enhanced when Red foxes were controlled from two islands (Marcström et al., 1989). Additionally, when sarcoptic mange killed many Red foxes in Sweden during the late 1970s and 1980s, mountain hare populations increased and their cyclicity vanished, but decreased again when Red foxes recovered from the disease (Kauhala et al., 1999; Newman et al., 2002). The hunting bags manage for Red fox in the Norway during 1976-19, 86 decreased the population, in contrasts, the hare population has ultimately increased (Selås and Vik, 2006). Goszczyński and Wasilewski (1992b) reported positive correlation between Red fox and hare density in central Poland.

In northern Pakistan, Karakoram range is occupied by globally important wildlife species such as snow leopard (Panthera uncia) and Tibetan wolf (Canis lepus) of which prey on or competitively displace red foxes (Roberts, 2005; Raza et al., 2015; Zaman et al., 2019b). Locally, Red fox are also a main predator of small mammals (e.g, Indian Pika (Ochotona roylei)) (Schneider, 2001). Major factors affecting declining Red fox population involve retaliatory killing for wheat crop damage and local poultry damages, local perception of the Red fox as a pest species (Maheshwari, 2018). Major threats affecting the decrease of hare population has been explained (Smith et al., 2005) as agricultural practices and human activities (Reichlin et al., 2006).

Assessments of the proportions of wildlife populations are essential to various phases of conservation and wildlife monitoring (Thomas et al., 2006), and hare abundance ecologically performing a vital role to regulate and maintain predator density, such as Red fox (Schneider, 2001). Similarly, predators density affect on the abundance, daily activities and spaitial distribution of their prey (Gilg et al., 2003). If predators vanished from a landscape, prey species become 'naive' to the predator (Berger et al., 2001). However, population density of hare from the interaction with predator density in study sites yet is unstudied and such experiments under the human disturbance are lacking (Weston et al., 2012). Besides the clear gap in the knowledge, the aims of the study were: 1), to determine a relationship between hare density and Red fox density, with the underlying hypothesis that hare density would be expected to be lower in areas of higher Red fox density, i.e., a positive correlation. 2), to determine an association between hare habitat association in 
areas of high Red fox densities, with the underlying hypothesis that hares would be expected to have a heightened density were Red fox burrows would be low. In this study, we focused on the population density of Cape hare (Lepus capensis) and their predator, i.e., Red fox (Vulpes vulpes montana), since the surmised predator can change in habitat assortment of medium-sized prey by predation risks (Frid and Dill, 2002).

\section{Materials and Methods}

\section{Study area}

We conducted our study in 2015-2017 at Shigar Valley $\left(8500 \mathrm{~km}^{2} ; 35^{\circ} 26^{\prime} \mathrm{N}\right.$, $75^{\circ} 44^{\prime} \mathrm{E}$ ) within the Karakorum range. The valley stretches approximately $80 \mathrm{~km}$ from the gateway of Shigar to Askole, Gilgit Baltistan Pakistan. The total survey area was approximately $\left(5700 \mathrm{~km}^{2}\right)$ involved the current range of hare and observed predator. The valleys are dry with the annual precipitation around $200 \mathrm{~mm}$ with a maximum of almost $600 \mathrm{~mm}$ at elevations of $3962 \mathrm{~m}$ and snow depth maximum of 0.304 meter and a minimum of 0.127 meter. Shigar 1, is located in Karakorum range part, at the elevation of $2527 \mathrm{~m}$ above sea level (asl) the North-East. The major plant species are Rosa webbiana, Hippophae rhamnoides, and Berberis lyceum. The habitat and vegetation composition described by Zaman et al. (2019a).

\section{Data collection}

\section{Cape hare and predator population density survey}

The field surveys of Cape hare population abundance were made in three consecutive years. Our study was conducted in summer (3 June to 5 September 2015) and in winter (25 October to 27 December) in 2016, and in the summer of 2017 (27 May to 29 August) in Shigar Valley. Hare population density was estimated based on line transects (Langbein et al., 1999). The basic assumptions of distance sampling were for estimation of flushing-out distances (1) perfect detection of hare at line centers; (2) distance quantity are the initial positions, before reactive movement; (3) correct count of grouped Cape hare (4); measurement of detection distances without fault, and; (5) representative sampling of the study area (Marques et al., 2001; Buckland et al., 2008). Perpendicular distances (x) were measured from the line to each detected Single/ cluster of Cape hare. $\mathrm{n}$ hare was detected at perpendicular distances. Animals at the truncation distance from the transect line $(\mathrm{w})$ and lengths of the transect $(\mathrm{L})$ were recorded. The surveyed area was $(\mathrm{a}=2 \mathrm{wL})$ within which $\mathrm{n}$ animals were detected. $\dot{\mathrm{Pa}}$ is the probability that a randomly chosen animal within the surveyed area was detected, and individual hare density (Ďs) was estimated by

$$
\check{\mathrm{D}} \mathrm{s}=\mathrm{n} / 2 \mathrm{WLP} \mathrm{Pa}
$$

To gain the estimated density of cluster, we multiplied by mean group size in the population, therefore:

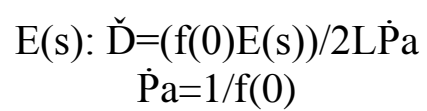


Probability is estimated of perpendicular distance at zero. E(s) estimated is expected cluster sized and $\check{D}$ is the estimated density of cluster, respectively (objects $/ \mathrm{km}$ ). We designed 8 sample plots with $9 \mathrm{~km}$ lengths and each sample plots were divided into $4 \times 4$ $\mathrm{km}$ grid size and 5 to 10 parellel array 50 meter transects were laid out in each samples plots, the distance between one sample plot to another was 5 and $10 \mathrm{~km}$. Each of the four study areas represented a huge variation in different habitat types, these were spaced between $3 \mathrm{~km}$ and $14 \mathrm{~km}$ apart in different selected sites (Fig. 1).

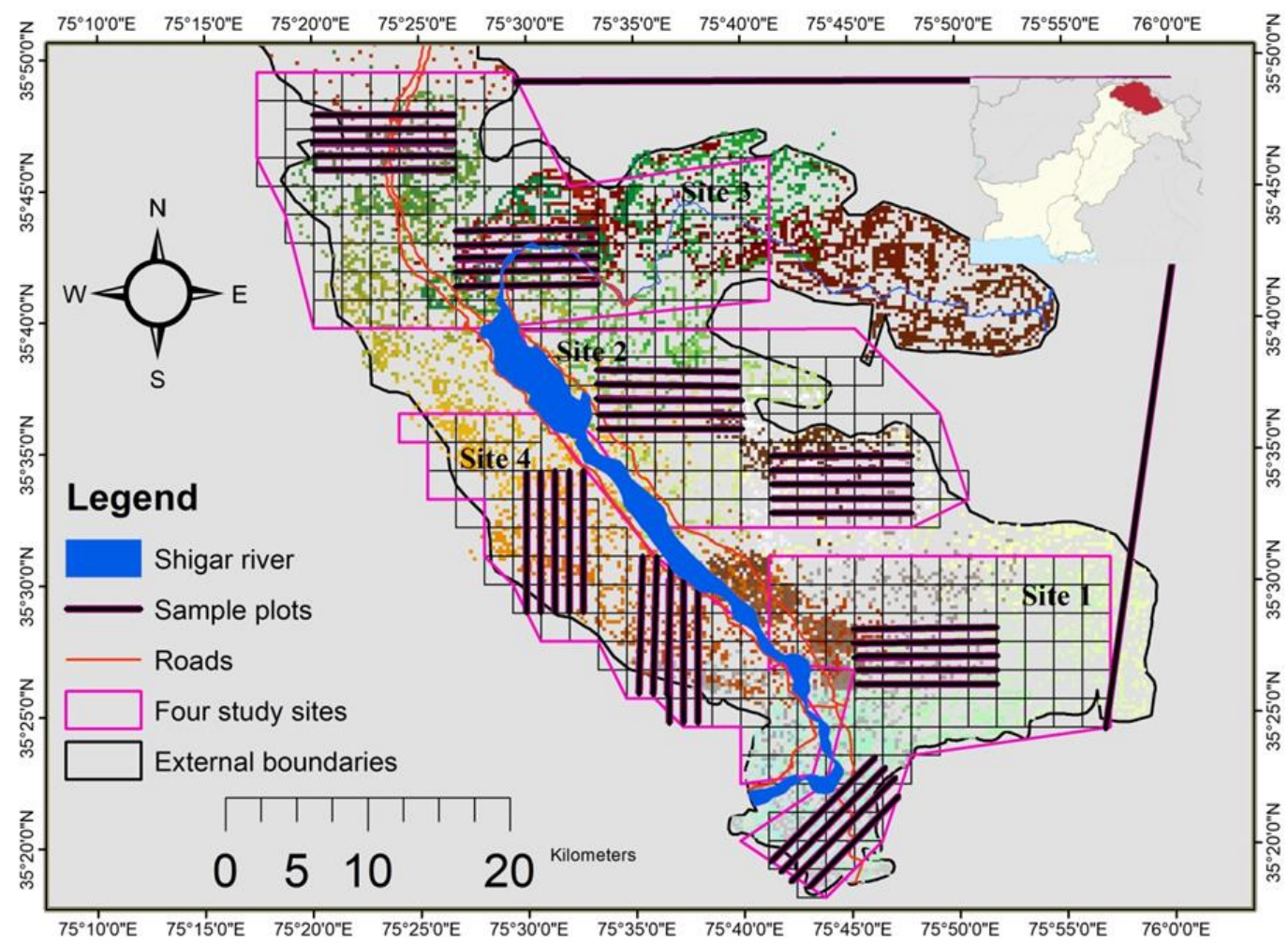

Figure 1. Three consecutive years sampling sites and four selected area, in Shigar Valley Karakorum range in both winter (25 Oct to 27, Dec-2015) and summer (3 June to 5 Sept2016 and 27 May to 29 August-2017. Hence, Shigar valley $80 \mathrm{~km}$ from gateway of Shigar to Askole, Gilgit Baltistan Pakistan

The study site 1, union council (UC) Marapi, extends from gateway of Sarfaranga $\left(35^{\circ} 21^{\prime} 47.81^{\prime \prime} \mathrm{N}, 75^{\circ} 44^{\prime} 24.82^{\prime \prime} \mathrm{E}\right)$ to Ghazapa $\left(35^{\circ} 25^{\prime} 5.05^{\prime \prime} \mathrm{N}, 75^{\circ} 45^{\prime} 11.65^{\prime \prime} \mathrm{E}\right)$, and Kanikernullah, Gangdrong nullah. Site 2, sampling areas were selected from UC Markunja nullah, Sarafa ranga thang, upper site of Chipping near historical Shigar fort $\left(35^{\circ} 25^{\prime} 27.43^{\prime \prime} \mathrm{N}, 75^{\circ} 44^{\prime} 34.83^{\prime \prime E}\right)$, to Taherping (3526'17.90"N, 7544'8.84"E), Chorkah ranga and extended from eastern part of valley to southern part. The 3rd study site containing sixteen different villages, UC Markuja extended from Bounpi ranga $\left(35^{\circ} 26^{\prime} 3.02^{\prime \prime} \mathrm{N}, 75^{\circ} 43^{\prime} 15.27^{\prime \prime} \mathrm{E}\right)$ to $\mathrm{UC}$ Chorkah ranga $\left(35^{\circ} 27^{\prime} 49.17^{\prime \prime} \mathrm{N}, 75^{\circ} 41^{\prime} 15.65^{\prime \prime} \mathrm{E}\right)$, Sildi, Hyderabad, Tiser. The study site 4, UC Gulapure and Barqzo contained Gulapur nullah $\left(35^{\circ} 22^{\prime} 56.84^{\prime \prime} \mathrm{N}, 75^{\circ} 42^{\prime} 11.43^{\prime \prime E}\right)$ and, Nialinullah, Alochorinullah, Markunja nullah, Marapi nullah, Chorkah nullah, Azamkhan to second gateway of Shigar valley linked to Bonpa Gulapur $\left(35^{\circ} 27^{\prime} 55.75^{\prime \prime} \mathrm{N}, 35^{\circ} 27^{\prime} 55.75^{\prime \prime} \mathrm{N}\right)$ near the catchment of the 
river. We only recorded distance for our targeted hare and each sample plots were sufficiently apart which was sufficient to avoid multiple recording of the same individuals across transects of different study areas (Smith et al., 2004). The abundance of hare pellet counts was used to estimate the hare abundance for broad-scale studies (Fa et al., 1999), counting fresh and old hare pellets within 10 plots of $10 \mathrm{~m} \mathrm{x} 10 \mathrm{~m}$ at $30 \mathrm{~m}$ intervals, eluding counts on or proximate latrines. The abundances of pellets were counted in 30 plots along each transect to derive pellet abundance indices (the number of presences divided by the number of plots multiplied by transects length as pellet abundance indices $/ \mathrm{km}$ ). We used Pellet uncleared plots methodology (Perry and Robertson, 2012) to check habitat association of Cape hare. It is assumed that the hare defecation rates were incredibly high (300 to 700 pellets/day (Welch, 1982). The direct estimation of relative population density of Red fox is given by this formula, $D=n / A$, where $\mathrm{n}$ represents a number of sample efforts with a particular survey time and A stands for sampling area in each site. Whenever a Red fox was encountered, time, date and number of individuals were noted (Raza et al., 2015). We estimated Red fox number of individuals $/ 4 \mathrm{~km}$ as described by Walton et al. (2017). We estimated Red fox abundance based on counts of active burrow entrances with a strip width of $30 \mathrm{~m}$, considering the number of active burrow entrances $/ 4 \mathrm{~km}$ as an index of Red fox abundance (Panek, 2009).

\section{Habitat covariates sampling}

We surveyed hare according to four different habitat features (Zaman et al., 2019a,b), and relative abundance, relative frequency, density and importance value index (IVI) of plant species were recorded as described by Mahmood et al. (2010). In a random stratified sample, 10 plots, each of the same size, were evaluated in all kinds of habitat types in each transect. The hare habitat types were extracted by polygons and we measured proximity factors: i.e., distance to rivers, roads, and agricultural lands and streams by ArcGIS (10.2) (Zaman et al., 2019a).

\section{Data analyses}

We calculated the seasonal density of hare population by the use of Distance 6.0 software (Thomas et al., 2010). The best model with the lowest delta akaike information criterion $(\triangle \mathrm{AICc}=0)$ values with the akaike information criterion (AICc) of the bestfitting model subtracted was selected for estimating population density (Thomas et al., 2010). We used Kolmogorov-Smirnov tests and quantile-quantile (Q-Q) plots to test the normality of data and data were normally distributed in selected sites (Thomas et al., 2010). We used Students samples t-test to compare the means of red Red fox population density. We used Pearson's correlation to analyze the relationships between pellets and burrow entrance abundance indices in two seasons. To measure the direct relationship between the hare and Red fox, we used the average means of population density in summer and winter. Multiple regression analysis was used to check seasonal habitat associations of hare pellet abundance index to the habitat variables in different sites (Broome, 2001). We used pellets abundance indices as dependent variables and independent categorical variables (habitat type) and ordinal variables (importance value index) for each habitat 10 plots of herbs, shrubs, trees, and grasses were used for analysis. The parameter estimates of variables were considered significant at $\mathrm{P}<0.05$. All data analyses were done in SPSS Statistics 21.0 (IBM SPSS, Chicago, IL, USA). 


\section{Results}

\section{Spatial distribution of Cape hare and their predator population density}

In summer, the population density of Cape hare in the selected site 3 was the highest and the lowest density of hare was found in selected site 1 (Table 1a). The average detection probability, Encounter rate and cluster size of Cape hare was the highest in selected site 1 (Table $1 b$, Fig. $2 b$ ). When using hazard rate key function with series expansion the observed and expected distances were significant (Table 1b). The lowest detection probability for hare was recorded in selected site 2, (Table 1b, Fig. 2c). The selected model key half-normal for Kolmogorov-Smirnov test was insignificant (Table 1b). In the selected site 4 (Fig. $2 d$ ) detection probability was low. Uniform normal key with extension key showed to be significant in Kolmogorov-Smirnov test. The detection probability, encounter rate and cluster size of hare in the study site 3, was low (Table 1b, Fig. 2a). Half-normal key function with series expansion revealed no significant differences between observed and expected distances (Kolmogorov-Smirnov test, Table $1 b$ ).

Table 1a. Summary of candidate models (4 selected sites, key models; hazard-rate, halfnormal, uniform and series expansion; cosine, simple-polynomial, harmite-polynomial), with an Akaike information criterion for small sample size $(A I C c)$ difference $(\triangle A I C c=0)$ of each Cape hare population density census (D) (animals per $\mathrm{km}$ ), and $95 \%$ confidence interval $(\mathrm{CI})$ in Shigar Valley, Karakorum range in both winter (25 Oct to 27, Dec-2015) and summer (3 June to 5 Sept - 2016 and 27 May to 29 August - 2017) Gilgit Baltistan Pakistan

\begin{tabular}{c|c|c|c|cc}
\hline Sites & Key models & AICc & D/km & Lower & Upper \\
\hline Winter & - & - & - & - & - \\
\hline $\mathbf{1}$ & Hazard rate/simple & 38.14 & 1.05 & $0.49-$ & $1.00-$ \\
$\mathbf{2}$ & Halfnormal/hermite & 15.79 & 1.40 & $1.19-$ & 1.9 \\
$\mathbf{3}$ & Hazardrate/simple & 18.14 & 1.80 & $1.0-$ & 2.7 \\
$\mathbf{4}$ & Uniform/simple & 15.38 & 1.38 & - & 1.94 \\
\hline Summer & - & - & - & $1.95-$ & 2.98 \\
$\mathbf{1}$ & Uniform/cosine, & 97.45 & 2.41 & $0.76-$ & 8.54 \\
$\mathbf{2}$ & Halfnormal/hermite & 21.06 & 2.55 & $2.62-$ & 14.42 \\
$\mathbf{3}$ & Halfnormal/simple & 14.36 & 6.15 & $1.76-$ & 12.37 \\
$\mathbf{4}$ & Uniform/cosine & 13.46 & 4.67 & & \\
\hline
\end{tabular}

Table 1b. The summary of observed and expected distances significant Kolmogorov-Smirnov test $(D n)$, and The average detection probability $(\dot{P} a)$, Encounter rate $(E r)(n /$ survey effort (se) and cluster size $(\check{D})$ standard error $( \pm S E)$, calculated from observation at different line transect of Cape hare in Shigar Valley, Karakorum range in both winter (25 Oct to 27, Dec - 2015) and summer (3 June to 5 Sept-2016 and 27 May to 29 August-2017)

\begin{tabular}{c|c|c|c|c|c}
\hline Sites & Er (n/se) & $\dot{\text { Pa }}$ & D & Dn & p \\
\hline Winter & - & - & - & - & - \\
\hline $\mathbf{1}$ & 95.7 & 17.2 & $2.999 \pm 0.160$ & 0.1276 & $<0.05$ \\
$\mathbf{2}$ & 45.9 & 10.10 & $3.259 \pm 0.179$ & 0.1276 & $<0.05$ \\
$\mathbf{3}$ & 5.71 & 13.1 & $2.957 \pm 0.196$ & 0.2038 & $<0.05$ \\
$\mathbf{4}$ & 10.2 & 12.6 & $1.361 \pm 0.345$ & 0.1471 & $<0.05$ \\
\hline Summer & - & - & - & - & - \\
\hline $\mathbf{1}$ & 57.0 & 42.2 & $1.146 \pm 0.274$ & 0.2226 & $<0.05$ \\
$\mathbf{2}$ & 74.00 & 13.7 & $1.028 \pm 1.162$ & 0.1205 & $>0.05$ \\
$\mathbf{3}$ & 77.80 & 20.70 & $2.162 \pm 2.501$ & 0.1628 & $>0.05$ \\
$\mathbf{4}$ & 85.7 & 19.4 & $1.048 \pm 0.168$ & 0.1103 & $<0.05$ \\
\hline
\end{tabular}



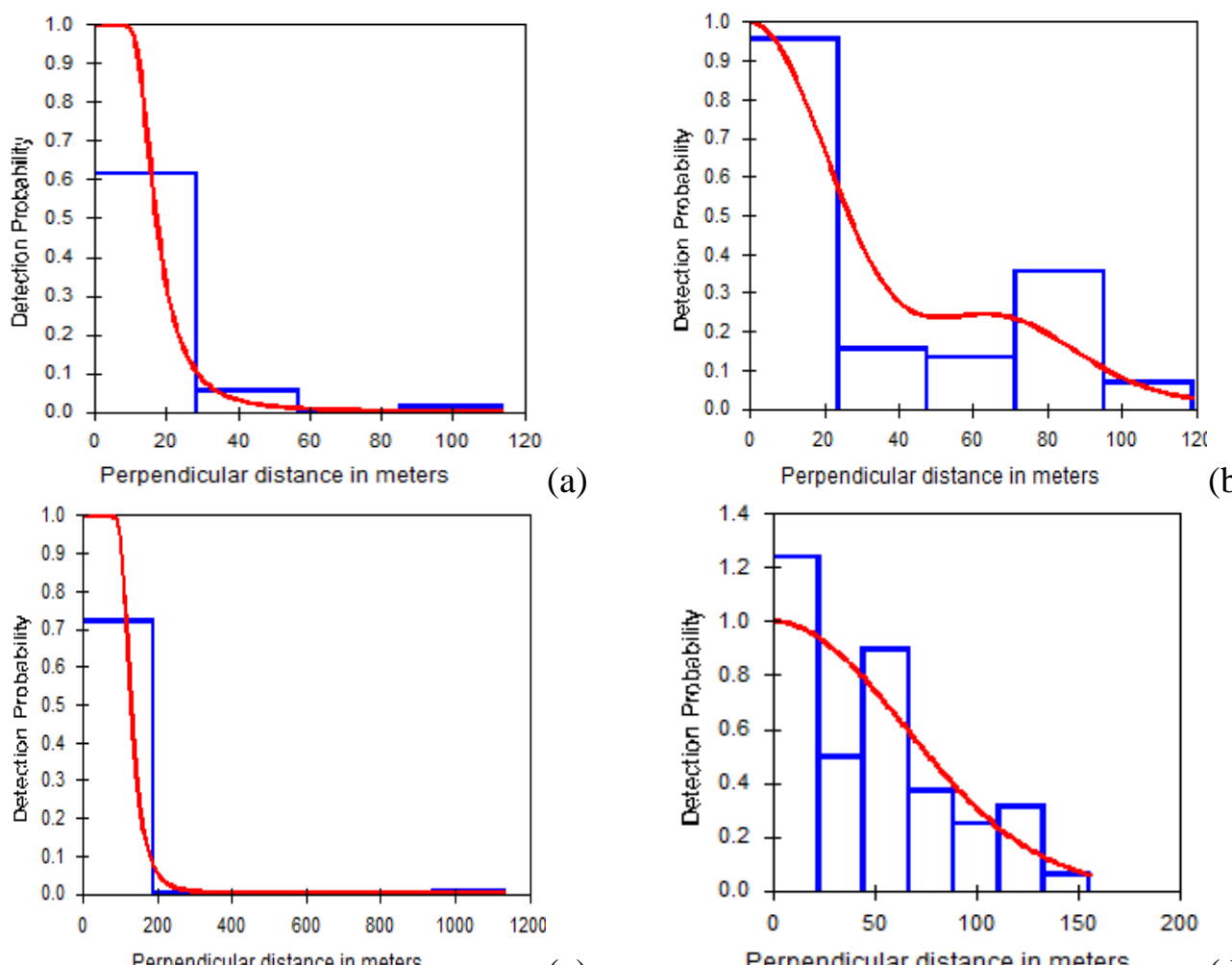

(b)

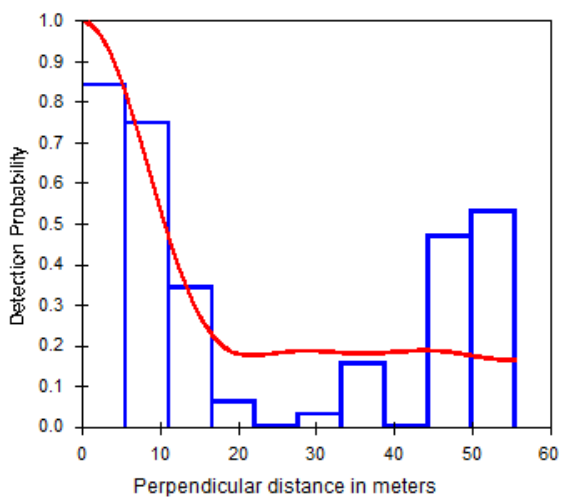

(c)

Perpendicular distance in meters

(d)
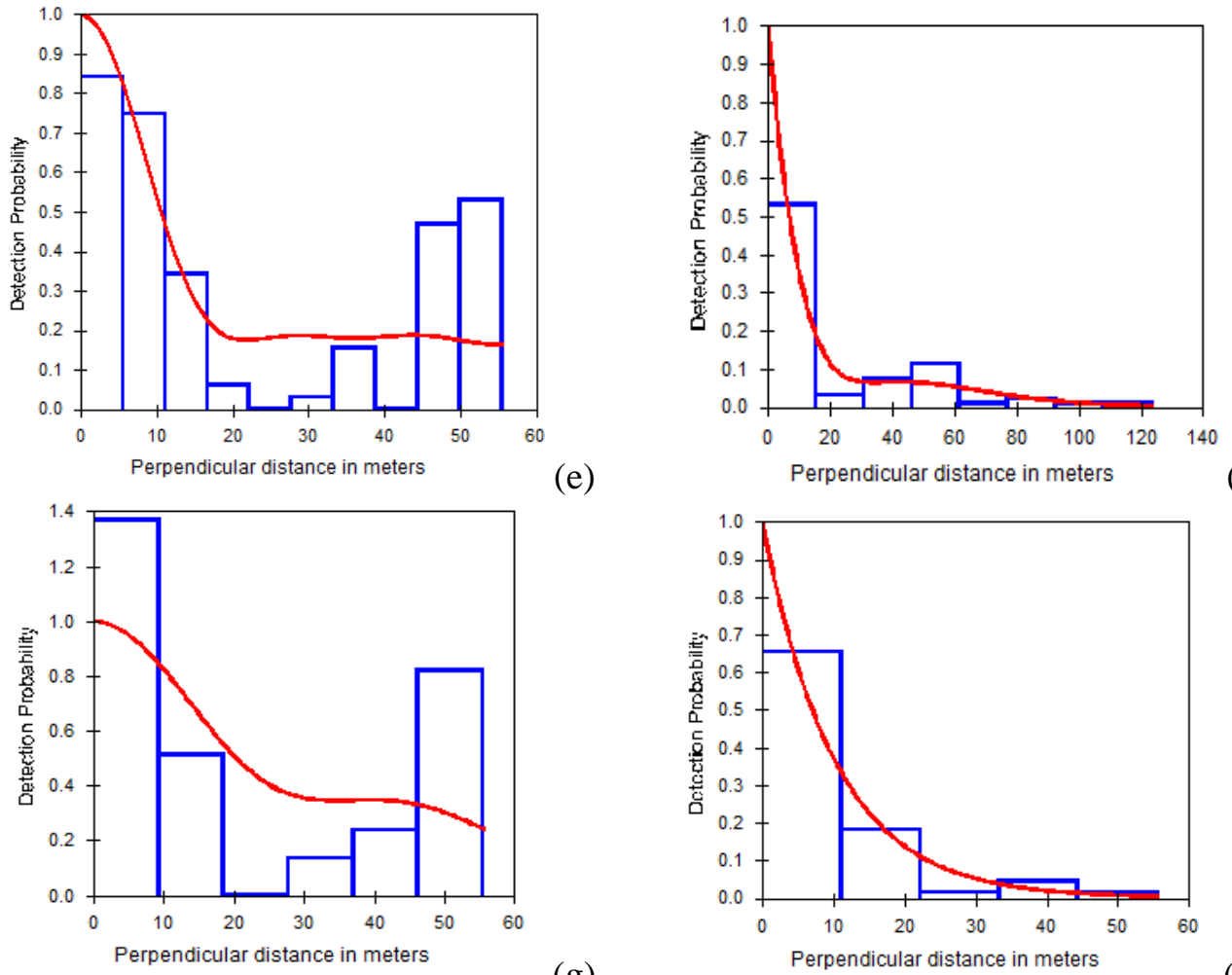

$(\mathrm{g})$

(h)

Figure 2. The perpendicular detection probability of hare using different model key in the summer in the site $3(a)$, site $1(c)$. In the site $4,(d)$. In the winter in the site $1,(e)$, site $2(f)$, in the site 3, $(g)$. In the site 4, $(h)$, hence the bar represented observed distance and the red curve showed the perpendicular distance at Shigar valley, Karakorum range in both winter (25 Oct to

27, Dec-2015) and summer (3 June to 5 Sept-2016 and 27 May to 29 August-2017) 
The relative density of Red fox was the lowest in the study site 3 and the highest in the selected site 1 (Table 2a).

In winter, the population density of Cape hare in the study site 3 was the highest and the lowest density of hare was found in selected site 2 (Table la). The average detection probability of Cape hare was the highest in the site 1 and average encounter rate was recorded and Hazard Rate key with extension key showed significant KolmogorovSmirnov test (Table 1b, Fig. 2e) and the lowest detection probability and encounter rate was observed in site 2. Half-normal key with extension key for Kolmogorov-Smirnov test was not significant (Table 1b, Fig. 2f). Detection rate and encounter rate was moderate in the site 4 (Table 1b, Fig. 2h) and observed and expected distance was significant (Table $1 b$ ) and, detection probability and encountered rate were accompanied by an expected cluster size; Uniform key with extension revealed significant differences for expected distance and observed distance (Table 1b). The relative density of Red fox was the lowest in site 4 and the highest in site 2 (Table 2a).

Table 2a. The Summary of summer and winter populations' estimation means with degree of freedom (Df) for Students $T$-test, $n$ number of surveyed in selected sites with particular time in both winter (25 Oct to 27, Dec - 2015) and summer (3 June to 5 Sept - 2015 and 27 May to 29 August - 2017) and (D) number of relatives density estimated from observation at different line transect of Red fox in Shigar Valley, Karakorum range Gilgit Baltistan Pakistan

\begin{tabular}{c|c|c|c|c|c|c}
\hline Sites & $\mathbf{n}$ & Means & PAI/km & $\mathbf{n}$ & means & ABE/4km \\
\hline Cape hare & - & - & - & Red fox & & \\
1 & 172 & $11.31 \pm 9.70$ & 13.9 & 31 & $4.8 \pm 3.3$ & 2.09 \\
2 & 89 & $1.21 \pm 0.52$ & 0.05 & 15 & $0.1 \pm 1.20$ & 0.21 \\
3 & 43 & $0.12 \pm 1.31$ & 0.91 & 24 & $2.1 \pm 7.9$ & 2.09 \\
4 & 37 & $0.02 \pm 0.12$ & 0.01 & - & - & - \\
\hline
\end{tabular}

Table 2b. Seasonal counting dens and pellets Indices for predator-prey, (n) showing sample sizes and means difference in four selected sites in Shigar Valley, Karakorum range in both winter (25 Oct to 27, Dec - 2015) and summer (3 June to 5 Sept - 2016 and 27 May to 29 August - 2017) Gilgit Baltistan Pakistan. Hence, PAI denoted pellet abundance indices $/ \mathrm{km}$ and $A B E$ represented number of active burrow entrances $/ 4 \mathrm{~km}$ in Shigar Valley

\begin{tabular}{|c|c|c|c|c|c|}
\hline Sites & $\mathbf{n}$ & $\mathrm{D} / \mathbf{4 k m}$ & Df & $\mathbf{T}$ & $\mathbf{P}$ \\
\hline \multicolumn{6}{|l|}{ Summer } \\
\hline 1 & 112 & 0.028 & 37 & 3.34 & $<0.05$ \\
\hline 2 & 73 & 0.018 & 40 & 2.77 & $<0.05$ \\
\hline 3 & 44 & 0.001 & 40 & 2.27 & $<0.05$ \\
\hline 4 & 37 & 0.009 & 26 & 2.76 & $<0.05$ \\
\hline Winter & & - & & - & \\
\hline 1 & 62 & 0.010 & 36 & 2.93 & $<0.05$ \\
\hline 2 & 76 & 0.015 & 44 & 3.38 & $<0.05$ \\
\hline 3 & 30 & 0.007 & 30 & 2.95 & $<0.05$ \\
\hline 4 & 33 & 0.008 & 32 & 1.97 & $<0.05$ \\
\hline
\end{tabular}

\section{The relationships between Cape hare and their predator population density}

The greatest abundance of pellets indices was recorded in site 1, and the lowest in site 2 (Table $2 b$ ), the greatest encounter rate of active burrows were in site 1 and the 
lowest in site 3 and in site 4 there were no encounter (Table $2 b)$. In summer, Red fox density was significantly positively $(\mathrm{r}=0.213 ; p<0.05)$ related to hare density in site 3 . Seasonal burrow entrance and pellets index negatively correlate $(\mathrm{r}=0.922 ; p<0.05)$ in site 1 . In winter, Red fox density was significantly positively $(\mathrm{r}=0.102 ; p<0.05)$ related to Cape hare density in site 2 . We found that seasonally hare pellet abundance indices were positively correlated with indices of herbs (site 1; site 2), grassland (site 1; site 2), shrubs (site 3; site 4), trees (site 3; site 4), distance to rivers (site 3), distance to agriculture land (site 2) and distance to roads (site 4) and streams (site 1; Table 3). Negative correlations were observed with distance to agricultural land (site 1; site 3; site 4), roads (site 1; site 2; Site 3), rivers (site 2) and streams (site 2; Table 3).

Table 3. Linear relationship between the hares (Pellet uncleared plots) pellets abundance indices and habitat factors with $95 \%$ confidence interval $(C L)$ in Shigar valley, Karakorum range in both winter (25 Oct to 27, Dec-2015) and summer (3 June to 5 Sept-2016 and 27 May to 29 August - 2017)

\begin{tabular}{c|c|c|c|c}
\hline Study sites & $\begin{array}{c}\text { Independent } \\
\text { Variables }\end{array}$ & Coefficients & P & $\begin{array}{c}\text { 95\% CI } \\
\text { Lower - upper }\end{array}$ \\
\hline \multirow{1}{*}{ Herbs index } & 0.505 & $<0.05$ & 0.015 to 0.994 \\
& Grasses index & 0.925 & $<0.05$ & 0.422 to 1.428 \\
& Distance to road & -0.327 & $>0.042$ to 0.613 \\
& Distance to agriculture & -0.032 & $<0.05$ & -0.050 to 0.606 \\
& Distance to stream & 0.644 & $<0.05$ & 0.357 to 0.935 \\
\hline \multirow{2}{*}{$\mathbf{3}$} & Herbs index & 0.365 & $<0.05$ & 0.167 to 0.563 \\
& Grasses index & 0.387 & $<0.05$ & 0.033 to 0.741 \\
& Distance to river & -0.278 & $<0.05$ & -0.012 to 0.569 \\
& Distance to agriculture & 0.277 & $<0.05$ & 0.007 to 0.569 \\
& Distance to road & -29.32 & $<0.05$ & -17.783 to 40.867 \\
& Distance to stream & -13.821 & $<0.05$ & -0.46 to 27.687 \\
\hline \multirow{2}{*}{4} & Shrubs index & 0.273 & $<0.05$ & 0.054 to 0.491 \\
& Tree index & 0.278 & $<0.05$ & 0.107 to 0.450 \\
& Distance to river & 0.175 & $<0.05$ & 0.019 to 0.330 \\
& Distance to agriculture & -0.139 & $<0.05$ & -0.083 to 0.887 \\
& Distance to road & -0.490 & $<0.05$ & -0.108 to 0.873 \\
\hline & Shrubs index & 0.300 & $<0.05$ & 0.120 to 0.481 \\
& Tree index & 0.338 & $<0.05$ & 0.165 to 0.510 \\
& Distance to road & 0.050 & $<0.05$ & 0.125 to 0.889 \\
& Distance to agriculture & -0.387 & $<0.05$ & -0.033 to 0.741 \\
\hline
\end{tabular}

\section{Discussion}

\section{Spatial relationships of predators and Cape hare population density relating to habitat factors}

We found that the detection probability of Cape hare in the summer (site 1 and site 4) and in the winter, site 1 and site 3 showed a higher broad shoulder in the histogram as compared to other selected sites. This situation led to a comparatively higher detection rate resulting in lower density estimates may influenced by biased or small sample size (Herrmann et al., 2010). It was an assumption that we were attentive to, that transects within dense vegetation show lower visibility despite the higher density, this is typical across the heterogeneous survey region (Buckland et al., 2001; Herrmann et al., 2010). While maximum detections of hares were single, we were attentive in counting hares in clusters, and regardless of vegetation structure (Rivera-Milán et al., 2015). 
Although there were a great number of Cape hares at $0 \mathrm{~m}$ distance from the $1 \mathrm{~km}$ length transect line. The $0 \mathrm{~m}$ distance assumption is critical (Buckland et al., 2001). Herrmann et al. (2010) studied spring Cape hare, and steenbok (Raphicerus campestris) densities in South Africa by distance sampling in different seasons in forestland with associated open land hare density, which was higher in summer. The European hare has been measured in numerous countries and its abundance has been found to be between 21 and 330/ ha, varying according to the landscape type (Smith et al., 2004). The abundance of lagomorph was counted in many countries using transects but was much higher than those found in our study area where e.g., Australia (25 rabbits/km, (Moreno et al., 2008)) and New Zealand (125 rabbits/km (Olsen et al., 2014)). European abundances of brown hares can extent densities in excess of 100 hares $\mathrm{km}^{2}$ (Smith et al., 2005). Seasonally Pellets abundance also differed among the habitat, but high counted in site 1. The defecation rates of mountain hares (Lepus timidus) vary with season (Hewson, 1989). Pellet abundance index was greater in the site 1. We used the uncleared way to calculation pellets abundance due to some transect not accessible for winter and Cape hare defecation rates were also high, similar results were found in previous results described by (Welch, 1982). The abundance of pellets was higher in site 1, for examples, the accessibility of food resources and escape covers also influenced on latrines site selection of hare (Krebs et al., 1995).

In this study, we found that the seasonal and spatial distribution of Red fox density was altered among the habitat, although we have not previously reported of Red fox density in the study area so it was difficult to compare spatial Red fox abundance. In summer we encountered the highest density of Red fox $0.028 / 4 \mathrm{~km}$ in site 1 (Table 2), and less than $0.009 / 4 \mathrm{~km}$ in site 4 , the highest den sites were encountered in site 1 $3.01 / 4 \mathrm{~km}$; site 1 , in winter Red fox density $(0.010 / 4 \mathrm{~km})$ was the highest for site 1 . Our density estimates were lesser because of revenge to damage, poisons, and inadequate baseline data reports available for Red fox in the current study area, than estimates found in areas of maximum density of Red fox in Europe (3.30 Red foxes $/ \mathrm{km}^{2}$, (Sarmento et al., 2009)). However, some English rural areas Red fox were recorded (0.64 Red foxes $/ \mathrm{km}^{2}$, (Heydon et al., 2000)) and in Portugal as well (0.63 Red foxes $/ \mathrm{km}^{2}$ (Sarmento et al., 2009)).

In the summer Red fox density was significantly positively related to hare density in the closed to open broadleaved or needle-leaved forest, for example Snow shoe hare (Lepus americanus) abundance is closely associated with habitat characteristics, and the primary reason for mortality for snow shoes hare is predation (Goszczyński and Wasilewski, 1992b). Seasonal Red fox burrow entrance were negatively correlated with hare pellets abundance in site 1, as others also report, according to those of the hares studies described by (Angelstam and Lindström, 1984). In this work, we investigated the distribution of Red fox per $4 \mathrm{~km}$ as considering that the variation in Red fox home range sizes $\left(0.95 \mathrm{~km}^{2}\right.$ to $358 \mathrm{~km}^{2}$; (Walton et al., 2017). It was not possible to census Red foxes using torch light counts in site 3, because of the large amount of dense vegetation (Heydon et al., 2000). We found that seasonally the Red fox utilizes dens for birthing and rearing offspring ('breeding dens') in the grassland and barren land, where higher accessibility afford less natural boulder, rock cervices dens as well as abundance of prey (Meia and Weber, 1992) in site 3 due to abundance of prey and shelters. We also expected that fuel wood collection and illegal hunting by local people reduced concealment throughout the landscape and increased the compensation of detection for example, den selection is influenced by prey availability in the cases of the Corsac Red 
fox (Vulpes corsac) (Murdoch et al., 2009), the Eurasian badger (Meles meles) and the Red fox (Márton et al., 2016). We assumed that high density of Red fox in site 1 and low density of Red fox in other habitats significantly depend on the abundance of prey species and avoid human conflicts.

Our study results explained that hare abundance is positively associated with vegetation such as shrubs, herbs, such a similar results also found in case of snowshoe hare (Lepus americanus) (Hodges et al., 2009). Roads are negatively linked with hare abundance (Roedenbeck and Voser, 2008). Hare abundance was also negatively associated with agricultural land at site 2 due to conflicts by farmers, such results were also described by (Santilli et al., 2015).

Agricultural land and roads were positively linked with hare abundance(Reichlin et al., 2006). The hare seasonal pellets abundance index was positively linked with herbs and trees , e.g. snow hare (Hodges et al., 2009). Similarly, Hodson et al. (2011) reported that shrubs and saplings provide lateral protective cover for hare. Furthermore, in Pakistan, the Cape hare prefers alpine meadows in the summer season while in winter it moved down to steppe meadows (Roberts, 2005).

\section{Conclusions}

Our finding also showed that Cape hare density plays a key role in the natal den site selection and spatial distribution of Red fox. Furthermore, we expected that prey density distribution, habitat association and behavioral response may result from the lethal (predation) or non-lethal (landscape fear) effect of a predator, or human. Humanwildlife interactions can result in conflict where perceived damage to livelihoods occurs in socio-economically poor areas. In the Shigar Valley, Karakorum Range, Pakistan, subsistence mixed farming is the predominant land use and Red foxes as well as preys are extensively persecuted. Understanding on the effects of human activity and habitat features of Red fox and Cape hare feeding behaviors in the region are lacking. The findings recommended that Red fox and Cape hare do not avoid human settlements area. In the future, further Red fox genetics studies are needed to be conducted with a focus on ecosystem functions via seed dispersal, carrion removal and regulation of prey populations. It is envisioned that this work can be offered to local authorities as the first piece of scientific literature for the area, serving as a valuable resource for local public education, and also for tourists and NGO community visitors of the Karakorum national park.

Acknowledgments. We would like to thank Dr. M. Anwar, M. Rais, T. Mahood, I. Hussain and Mr. J. Hussain for their moral support. We would also like to thank Mr. N. J. Roberts et al in Feline Research Center of National Forestry Administration, for their useful comments for revising the manuscript. This work was supported by the Fundamental Research Funds for the Central Universities (2572017PZ14) and NSFC (31872241; 31572285).

\section{REFERENCES}

[1] Angelstam, P. E., Lindström, P. W. (1984): Role of predation in short-term population fluctuations of some birds and mammals in fennoscandia. - Oecologia 62(2): 199-208.

[2] Arnold, G. W., Dudzinski, M. (1978): Ethology of free-ranging domestic animals. Elsevier Scientific Publishing Co. 
[3] Berger, J., Swenson, J. E., Persson, I. L. (2001): Recolonizing carnivores and naive prey: Conservation lessons from pleistocene extinctions. - Science 291(5506): 1036-1039.

[4] Broome, L. S. (2001): Density, home range, seasonal movements and habitat use of the mountain pygmy-possum burramys parvus (marsupialia: Burramyidae) at mount blue cow, Kosciuszko national park. - Austral Ecology 26(3): 275-292.

[5] Brown, J. S., Laundré, J. W., Gurung, M. (1999): The ecology of fear: Optimal foraging, game theory, and trophic interactions. - Journal of mammalogy 80(2): 385-399.

[6] Buckland, S. T., Anderson, D. R., Burnham, K. P., Laake, J. L., Borchers, D. L., Thomas, L. (2001): Introduction to distance sampling: Estimating abundance of biological populations. - Oxford University press, 432p.

[7] Buckland, S. T., Marsden, S. J., Green, R. E. (2008): Estimating bird abundance: Making methods work. - Bird Conservation International 18(S1): S91-S108.

[8] Creel, S. (2011): Toward a predictive theory of risk effects: Hypotheses for prey attributes and compensatory mortality. - Ecology 92(12): 2190-2195.

[9] Fa, J. E., Sharples, C. M., Bell, D. J. (1999): Habitat correlates of european rabbit (oryctolagus cuniculus) distribution after the spread of rvhd in Cadiz province, Spain. Journal of Zoology 249(1): 83-96.

[10] Frid, A., Dill, L. (2002): Human-caused disturbance stimuli as a form of predation risk. Conservation Ecology 6(1): 11.

[11] Gilg, O., Hanski, I., Sittler, B. (2003): Cyclic dynamics in a simple vertebrate predatorprey community. - Science 302(5646): 866-868.

[12] Goszczyński, J., Wasilewski, M. (1992a): Predation of Red foxes on a hare population in central Poland. - Acta theriologica 37(4): 329-338

[13] Hearn, B. J., Keith, L. B., Rongstad, O. J.(1987): Demography and ecology of the arctic hare (lepus arcticus) in southwestern Newfoundland. - Canadian journal of zoology 65(4): 852-861.

[14] Herrmann, E., Stenkewitz, U., Kamler, J. F. (2010): Distance sampling for estimating springhare, cape hare and steenbok densities in South Africa. - South African Journal of Wildlife Research 40(1): 87-92.

[15] Hewson, R. (1989): Grazing preferences of mountain hares on heather moorland and hill pastures. - Journal of Applied Ecology 26(1): 1-11.

[16] Heydon, M. J., Reynolds, J. C., Short, M. J. (2000): Variation in abundance of Red foxes (vulpes vulpes) between three regions of rural Britain, in relation to landscape and other variables. - Journal of Zoology 251(2): 253-264.

[17] Hodges, K. E., Mills, L. S., Murphy, K. M. (2009): Distribution and abundance of snowshoe hares in Yellowstone national park. - Journal of Mammalogy 90(4): 870-878.

[18] Hodson, J., Fortin, D., Bélanger, L. (2011): Changes in relative abundance of snowshoe hares (lepus americanus) across a 265-year gradient of boreal forest succession. Canadian Journal of Zoology 89(10): 908-920.

[19] Kauhala, K., Helle, P., Helle, E., Korhonen, J. (1999): Impact of predator removal on predator and mountain hare populations in Finland. - Annales Zoologici Fennici 36(3): 139-148.

[20] Krebs, C. J., Boutin, S., Boonstra, R., Sinclair, A., Smith, J., Dale, M. R., Martin, K., Turkington, R. (1995): Impact of food and predation on the snowshoe hare cycle. Science 269(5227): 1112-1115.

[21] Lima, S. L., Dill, L. M. (1990): Behavioral decisions made under the risk of predation: A review and prospectus. - Can J Zool 68(4): 619-640.

[22] Lima, S. L. (1998): Nonlethal effects in the ecology of predator-prey interactions. Bioscience 48(1): 25-34.

[23] Macdonald, D. W. (1983): The ecology of carnivore social behaviour. - Nature 301(5899): 379.

[24] Macdonald, D. W. (2004): Dramatis personae. Wild Canids-an introduction and dramatis personae. - The Biology and Conservation of wild canids: 4-35. 
[25] Maheshwari, A. (2018): Foraging habits of the red Red fox vulpes vulpes (mammalia: Carnivora: Canidae) in the Himalaya, India. - Journal of Threatened Taxa 10(10): 1241812421.

[26] Mahmood, S., Mahmood, T., Rais, M., Qureshi, I., Nadeem, M. (2010): A comparative study on the populations and habitats of the grey francolin francolinus pondicerianus and the black francolin francolinus francolinus in Lehri nature park, Punjab, Pakistan. Podoces 5(1): 42-53.

[27] Marcström, V., Keith, L. B., Engren, E., Cary, J. R. (1989): Demographic responses of arctic hares (lepus timidus) to experimental reductions of red Red foxes (vulpes vulpes) and martens (martes martes). - Canadian Journal of Zoology 67(3): 658-668.

[28] Marques, F. F., Buckland, S. T., Goffin, D., Dixon, C. E., Borchers, D. L., Mayle, B. A., Peace, A. J. (2001): Estimating deer abundance from line transect surveys of dung: Sika deer in southern Scotland. - Journal of Applied Ecology 38(2): 349-363.

[29] Márton, M., Markolt, F., Szabó, L., Kozák, L., Lanszki, J., Patkó, L., Heltai, M. (2016): Den site selection of the European badger, meles meles and the red Red fox, vulpes vulpes in Hungary. - Folia Zoologica 65(1): 72-80.

[30] Meia, J., Weber, J. (1992): Characteristics and distribution of breeding dens of the red Red fox (vulpes vulpes) in a mountainous habitat. - Zeitschrift für Saugetierkunde 57: 137-143.

[31] Møller, A. P. (2008): Flight distance and population trends in European breeding birds. Behavioral Ecology 19(6): 1095-1102.

[32] Moreno, S., Beltrán, J. F., Cotilla, I., Kuffner, B., Laffite, R., Jordán, G., Ayala, J., Quintero, C., Jiménez, A., Castro, F. (2008): Long-term decline of the European wild rabbit (oryctolagus cuniculus) in southwestern Spain. - Wildlife Research 34(8): 652658.

[33] Murdoch, J. D., Munkhzul, T., Buyandelger, S., Reading, R. P. (2009): Body size and sexual dimorphism among a population of corsac and red Red foxes in central Mongolia. - Mammalia 73: 72-75.

[34] Newman, T. J., Baker, P. J., Harris, S. (2002): Nutritional condition and survival of red Red foxes with sarcoptic mange. - Canadian journal of zoology 80(1): 154-161.

[35] Olsen, J., Cooke, B., Trost, S., Judge, D. (2014): Is wedge-tailed eagle, aquila audax, survival and breeding success closely linked to the abundance of European rabbits, oryctolagus cuniculus? - Wildlife Research 41(2): 95-105.

[36] Panek, M. (2009): Factors affecting predation of red Red foxes vulpes vulpes on brown hares lepus europaeus during the breeding season in poland. - Wildlife Biology 15(3): 345-349.

[37] Perry, M. E., Robertson, A. W. (2012): Cleared and uncleared pellet plots as indices of brown hare density. - New Zealand Journal of Ecology 36(2): 1.

[38] Preisser, E. L., Bolnick, D. I., Benard, M. F. (2005): Scared to death? The effects of intimidation and consumption in predator-prey interactions. - Ecology 86(2): 501-509.

[39] Raza, G., Mirza, S. N., Anwar, M., Hussain, I., Khan, S. W., Khalil, A., Nawaz, M. A., Naseer, A. (2015): Population and distribution of himalayan ibex, capra ibex sibrica, in Hushe valley, central Karakoram national park, Pakistan. - Pakistan Journal of Zoology 47(4): 1025-1030.

[40] Reichlin, T., Klansek, E., Hackländer, K. (2006): Diet selection by hares (lepus europaeus) in arable land and its implications for habitat management. - European journal of wildlife research 52(2): 109-118.

[41] Rivera-Milán, F. F., Bertuol, P., Simal, F., Rusk, B. L. (2015): Distance sampling survey and abundance estimation of the critically endangered Grenada Dove (Leptotila wellsi). The Condor 117(1): 87-93.

[42] Roberts, T. J. (2005): Field guide to the large and medium-sized mammals of Pakistan. Oxford University Press. 
[43] Roedenbeck, I. A., Voser, P. (2008): Effects of roads on spatial distribution, abundance and mortality of brown hare (lepus europaeus) in Switzerland. - European Journal of Wildlife Research 54(3): 425-437.

[44] Santilli, F. (2007): Factors affecting brown hare (lepus europaeus) hunting bags in Tuscany region (central Italy). - Hystrix, Italian Journal of Mammalogy 17.2-4372.

[45] Santilli, F., Bagliacca, M., Paci, G. (2015): Density and habitat use of sympatric brown hares and European rabbits in a mediterranean farmland area of Tuscany (central Italy). Ethology Ecology \& Evolution 27(2): 233-243.

[46] Sarmento, P., Cruz, J., Eira, C., Fonseca, C. (2009): Evaluation of camera trapping for estimating red Red fox abundance. - The Journal of Wildlife Management 73(7): 12071212.

[47] Schneider, M. F. (2001): Habitat loss, fragmentation and predator impact: Spatial implications for prey conservation. - Journal of Applied Ecology 38(4): 720-735.

[48] Selås, V., Vik, J. (2006): Possible impact of snow depth and ungulate carcasses on red Red fox (vulpes vulpes) populations in Norway, 1897-1976. - Journal of Zoology 269(3): 299-308.

[49] Smith, R. K., Jennings, N. V., Robinson, A., Harris, S. (2004): Conservation of european hares lepus europaeus in Britain: Is increasing habitat heterogeneity in farmland the answer? - Journal of Applied Ecology 41(6): 1092-1102.

[50] Smith, R. K., Vaughan, N. J., Harris, S. (2005): A quantitative analysis of the abundance and demography of european hares lepus europaeus in relation to habitat type, intensity of agriculture and climate. - Mammal review 35(1): 1-24.

[51] Stankowich, T., Blumstein, D. T. (2005): Fear in animals: A meta -analysis and review of risk assessment. - Proceedings of the Royal Society of London B: Biological Sciences 272(1581): 2627-2634.

[52] Thomas, L., Laake, J., Strindberg, S., Marques, F., Buckland, S., Borchers, D., Anderson, D., Burnham, K., Hedley, S., Pollard, J. (2006): Distance 5.0. Release 2. - Research unit for wildlife population assessment, University of St. Andrews, United Kingdom.

[53] Thomas, L., Buckland, S. T., Rexstad, E. A., Laake, J. L., Strindberg, S., Hedley, S. L., Bishop, J. R., Marques, T. A., Burnham, K. P. (2010): Distance software: Design and analysis of distance sampling surveys for estimating population size. - Journal of Applied Ecology 47(1): 5-14.

[54] Waggett, R. J., Buskey, E. J. (2007): Calanoid copepod escape behavior in response to a visual predator. - Marine Biology 150(4): 599-607.

[55] Walton, Z., Samelius, G., Odden, M., Willebrand, T. (2017): Variation in home range size of red Red foxes vulpes vulpes along a gradient of productivity and human landscape alteration. - PloSone 12(4): e0175291.

[56] Welch, D. (1982): Dung properties and defecation characteristics in some scottish herbivores, with an evaluation of the dung -volume method of assessing occupance. Acta theriologica 27(15): 191-212.

[57] Weston, M., McLeod, E. M., Blumstein, D., Guay, P. J. (2012): A review of flightinitiation distances and their application to managing disturbance to Australian birds. Emu-Austral Ornithology 112(4): 269-286.

[58] Weterings, M. J., Zaccaroni, M., van der Koore, N., Zijlstra, L. M., Kuipers, H. J., van Langevelde, F., van Wieren, S. E. (2016): Strong reactive movement response of the medium-sized European hare to elevated predation risk in short vegetation. - Animal behaviour 115: 107-114.

[59] Zaman, M., Tolhurst, B. A., Zhu, M., Jiang, G. (2019a): Increased flight initiation distance (fid) in golden marmots (marmota caudata aurea) responding to domestic dogs in a landscape of human disturbance. - Animals 9(9): 605.

[60] Zaman, M., Tolhurst, B., Zhu, M., Heng, B., Jiang, G. (2019b): Do red Red foxes (vulpes vulpes) increase the detectability of scent marks by selecting highly conspicuous substrates? - Journal of Ethology and Animal Science 2(2): 000113. 